\title{
Biomimicry and circular metabolism for the cities of the future
}

\author{
T. Spiegelhalter \& R. A. Arch \\ Florida International University, USA
}

\begin{abstract}
Cities play a crucial role in the fight against climate change. They already account for over half of the world's population and it is projected that six out of every ten people on earth will be living in cities by 2025. Cities and their residents are also responsible for approximately 80 percent of the GHGs emitted worldwide. All of this is common knowledge, endlessly discussed, widely published, and yet, incredibly, industrial and urban expansion carries on. Historically, societies unable to solve their environmental crisis have either migrated or become extinct. Early societies may have even achieved a better consistency among their resource extraction, transformation, use, life cycle, and flow, a viscosity more in tune with their ecosystems than our own. This research reviews how the natural world has provided ideal models of resource balance that have evolved over millions of years. Native ecosystems are composed of an abundance of life forms that utilize local resources in a way that is synergistically supportive of each other. Therefore, cities themselves must be viewed as complex ecological systems and this attitude must include any approach to designing cities and managing their use of resources. No cities in the world have yet to succeed in fully implementing a complete, integrated, circular metabolism resource plan. However, the two most important emerging cities in Europe are examined in this research. The author presents 2 city case studies, both pertaining to circular metabolism for local municipalities. The way these cities implement resource saving strategies and globally benchmark the life-cycle of their urban systems are examined. The author also discusses how they are biomimicking nature towards becoming carbon-neutral cities of the future.
\end{abstract}

Keywords: sustainability, biomimicry, circular metabolism, low-carboneconomy, urban ecology. 


\section{Towards zero-fossil-energy-infrastructures}

Nature has for millions of years demonstrated how numerous complex systems can work together in resource cycles that are continuously renewable and recycled. These systems are founded on the basic and contextual principle of climatic alignment, where resources from the sun, water, and earth combine to support life. Today the vital difference in city resource planning is that the scale of the resource and environmental impact crisis is no longer regional but global and it involves all living things in the entire planet. We do know that cities are where life is often at its most precarious, it is also where we have the greatest tangible opportunity for improvement, intervention, and radical change. Cities of the future must no longer be zoned as today, in linear, isolated one-activity zones but rather they will resemble the more mixed use richly layered cities of the past. Living, working, learning, and leisure should overlap and be housed in continuous, varied, and changing zero-fossil-energy operated, and flexible resource efficient infrastructures. Cities only survive because of human, material, and communication networks with their hinterlands or bioregions by placing them into a broader geographic context. Successful universal sustainability assessments and ecological foot printing can only be realistically applied for the purpose of the interrelated life cycle of systems, materials, and integrated land-use planning in this wider geophysical perspective.

\subsection{Closed loop systems and feedback loops}

Accordingly, a city's ecosystem has to have built-in mechanisms that selfregulate or sustainably manage its resource input and output flows, its recycled material flows, and its metabolic balances over time. The regulating mechanisms for such urban systems need to be based on measured "feedback loops," for continued improvements. In comparison nature works with small feedback loops, constantly learning, adapting, and evolving. We can also benefit from these processes in urban management, by evolving our designs in repeated steps of observation, evaluation, reiteration, and by applying them constantly throughout our own sustainable design exploration and implementation in urban planning.

\subsection{Biomimicry, Low-Carbon-Economy (LCE), and Industrial Ecology (IE)}

The field of Biomimicry (from bios meaning life and mimesis meaning to imitate) serves as an ancient concept for science that examines nature's occurring phenomena, processes, and elements. It emulates the natural environment to solve human problems sustainably in regards to habitat/location, climate, nutrient, social, and temporal conditions. Biomimicry suggest that there should be living within natural limits, because we are dependent on nature. However, the way in which we experience such constraints is always mediated by our technological, cultural, and social-economic systems. Nature as a model for biomimicry largely presents us still with mysteries beyond our comprehension to 
improve sustainable practice. The most striking difference between human technologies and living structures is that human artifacts are manufactured or stick-and-build and living things are grown. Related to this, living things are self-sufficient organisms, which also self-repair and reproduce. In contrast manmade structures like buildings only make sense when fitted into the complex social-economic and cultural networks of human society. They depend on outside support through massive infrastructural resource inputs to operate and maintain the city's survival.

Since we are still far away from the highly efficient natural processes of selfrepair and reproduction of cities, new infrastructural innovations have the possibility to shift from linear industrial processes to closed loop systems. In other words, open loop systems in which resources and capital investments move through the system to become waste can shift to closed loop systems where wastes and other products become inputs for new processes. Much of this closed loop systems integration thinking is based on the concepts of the Low-CarbonEconomy (LCE) and Industrial Ecology (IE), which proposes a view of industrial systems as being part of an interrelated complex ecosystem. It is the idea that we should model our systems after natural ones if we want to be sustainable. The aim of all three theories (Biomimicry, LCE, and IE) is to integrate all aspects of the city around technologies that produce energy and materials with little or no GHG emission. Therefore, around populations, buildings, machines and devices which use those energies and materials efficiently, and dispose of or recycle its wastes so as to have a minimal or no output of GHGs.

Cities generally have multilayered systems and sub-systems for land usage, such as services, utilities, industry, offices, housing, and transportation. The concentration of the city's multidisciplinary operation, maintenance, and repair greatly facilitates interaction between diverse people and businesses, benefiting all parties in the process. Big cities or metropolis, usually have associated suburbs and urban sprawl, creating numerous business commuters traveling to urban centers of employment within different peak times. Each city system is a simplified interpretation of reality whose behaviors can be 'predicted' through real-time assessments and scenario modeling, although the various structural complexities can make it difficult to fully understand the system's behaviors which may lead to rebound effects. For example, due to unforeseen behavioral change of users or consumers in a certain peak time, a measure taken to improve environmental performance could lead to disturbances or collapse of the system. This may mean a shift from a more mechanistic view of systems to one where sustainability is viewed as an emergent property of a complex structure of interchanging cycles, which requires different agent based modeling techniques. Biomimicry in the context of a city can be best seen by the city's life-cycle planning and assessment implying all potential environmental impacts caused by a product, system, or building project during its life cycle. This includes raw material extraction and processing, manufacture, use/operation, maintenance, reuse, and recycling as new circular resource input process. 


\section{Two eco-cycle case studies: Freiburg-Rieselfeld, Vauban, and Stockholm's Hammarby Sjöstad}

The following two examples demonstrate how city resource use with natural relationships at the urban scale can be seen as "closed-loop" or "circular metabolism", where current linear resource input move towards a circular cycle, and where renewable energy is used and waste is recovered as resource. Both district examples are biomimicking nature to overlap other social-economic and cultural-technological fields, which are leading to innovation for significant resource conservation and GHG-reduction to achieve the UN Intergovernmental Panel on Climate Change (IPCC) targets [1].

\subsection{Case study no. 1 \\ Freiburg, Germany - Two new districts Rieselfeld and Vauban}

Coordinates $47^{\circ} 59^{\prime} 0^{\prime \prime} \mathrm{N} 07^{\circ} 51^{\prime} 0$ " E, Elevation $278 \mathrm{~m}$

Area $153.07 \mathrm{~km}^{2}$ of which $40 \%$ forest

Population Urban district: 225,000 (2009), City subdivisions: 41 districts

Density $1,421 / \mathrm{km}^{2}$

Annual Solar Radiation: $1,117 \mathrm{~kW} / \mathrm{m}^{2}$, and 1,800 hrs/year sunshine

Freiburg, a historic town in Southwest Germany, has been leading environmental policy and practice for over two decades. Its two districts Vauban and Rieselfeld have generated worldwide interest for their sustainable redevelopment projects of former brownfields towards low-energy communities. With its current 225,000 inhabitants, Freiburg has been a university town for 550 years and has about 1 million overnight guests per year with the highest peak in summer and fall, of which $1 / 3$ are coming from abroad.

Freiburg launched an integral urban development master plan in the 1960's and in the 70s it successfully formed the first anti-nuclear movement. In 1986 it started an aggressive climate protection campaign to shift from fossil energy to renewable energy use wherever possible. The share of nuclear powered electricity has been reduced from 60 to less than 30 percent in 2005 . In 1992, Freiburg endorsed the Local Agenda 21 of the UN Conference on Environment and Development in Rio de Janeiro, and signed the Aalborg Charter in 1996, with the goals of reducing 9 tons of $\mathrm{CO} 2$ per annum and person, by 25 percent in 2010 and by 40 percent in 2050. Despite best efforts, Freiburg will presumably fail to reach its original goal of 25 percent less greenhouse gases by 2010 . However, this was regarded as an incentive by the city to redouble climate protection efforts. In the summer of 2007, resulting from a climate protection report by the Eco-Institute in Freiburg, the municipal council decided to proceed with its climate protection concept and raised the benchmark even higher to reduce 40 percent GHGs by 2030 [2]. 


\subsection{Social-cultural and techno-economical energy policy}

To reach the benchmarks stated above, Freiburg has implemented numerous innovative measures. Almost 50 percent of the city's electricity is generated by combined heating and power plants (CHP) using biogas from landfills and sewage treatment facilities using waste heat from one process to run another process that requires a lower temperature. In addition, private and public solar wind and geothermal energy sources add up to nearly zero fossil energy use by 2030. Biomass is mostly used for district heating in both Vauban and Rieselfeld and there are 90 small scale CHP all over the city. Germany's Packaging Ordinance together with high charges for waste management helped to significantly increase waste recycling and processing in Freiburg. Customers have the right to strip packaging off products at checkout and leave it there, so that producers reduce their packaging beforehand. Non-recyclable waste from the region is incinerated at thermal waste treatment plant supplying electricity for 25,000 households since 2005. Energy generated from the fermentation of bioorganic wastes covers two percent of Freiburg's energy demand and will increase until 2030.

Resource conservation strategies are implemented on all city levels by using publically accessible benchmarking tools and by conducting real-time buildings energy use and CO2 emissions auditing. They build and retrofit energy efficient, and promote sustainability among suppliers, employees, and other stakeholders through advocacy, marketing activity, $R \& D$, education, and training. Climate protection implementations are increasing in all fields of energy, mobility, purchasing, waste management, agriculture, and forestry. There are subsidy programs for passive and active solar design strategies such as solar envelope master planning (i.e. more than $10 \mathrm{MW}$ in-stalled PV as of 2009). Other energy saving programs include the use of wind ( 5 windmills, each 1,8 MW), biomass, geothermal, hydro-power, high-density public transport and bicycle networks, low energy passive house, zero fossil energy, water conservation, and energy building standards that support the ambitious goals for GHGs reduction by 40 percent in 2030. The city's waste management counting has a current 70 percent rate through intensive city wide implementation strategies based on the principles of Avoiding/Reducing, Re-using, and Recycling waste.

\subsection{Mobility and public space}

In 1969, the City of Freiburg developed an urban transport policy by designing a compact city with walk able neighborhoods that include decentralized services and markets, which gives preference to environment-friendly modes of movement (pedestrian traffic, cycling, and local public transport). The city was rewarded for its efforts with the "European Local Public Transport Award". Between 1982 and 2009, the contribution of transport with bike, trams, and buses to the city's volume of traffic increased from 15 to 70 percent, whereas the distances driven by motor vehicles decreased from 38 to 30 percent. Ninety percent of the residents live in $30 \mathrm{~km} / \mathrm{h}$ reduced-traffic zones with direct accessibility to public transportation of low speed and long distance high speed 
trains, and are connected to the $500 \mathrm{~km}$ bike lane network. Compared with other cities in Germany, Freiburg has the lowest motor vehicle density, with 423 motor vehicles per 1,000 people. Sixty five percent of people live in the catchment area of a tram stop and 98 percent close to a bus stop.

\subsection{Landscape and biodiversity}

With an area of 6,400 hectares (43 percent of the city's territory) Freiburg has the largest communal forest in Germany and 50 percent of the area is a landscape reserve plus 9 water areas (1792 hectares) are environmentally protected. According to the guidelines of the European biological reserve network NATURA 2000, close to 3,500 hectares of landscape are protected. Forest Stewardship (FSC) certifications of the municipal forest (5,000 hectares) are status quo and public parks and playgrounds (696 hectares) are interconnected through a greenbelt of biotopes, urban landscapes, bike lanes and public transportation systems [3].

\subsection{District Rieselfeld}

Planning for Rieselfeld started in 1992 and it is projected that by year 2012, this district will contain 4,200 apartments for 12,000 people on an area of 70 hectares of former sewage treatment fields. Early in 2008, more than 8,200 people were living in approximately 3,200 apartments, built by more than 110 private building contractor societies and investors. The urban development concept includes mixed-used, high density block structures with interconnected courtyards, green spaces, recycling stations, and playgrounds, as well as intensive bicycle paths, and traffic-calmed streets, where children are allowed to play and experiment. A consistent water concept and consideration of native micro-climatic aspects that restores and protect natural biotopes are other components. All rain and storm water is managed on site and rainwater is collected and reused in most buildings.
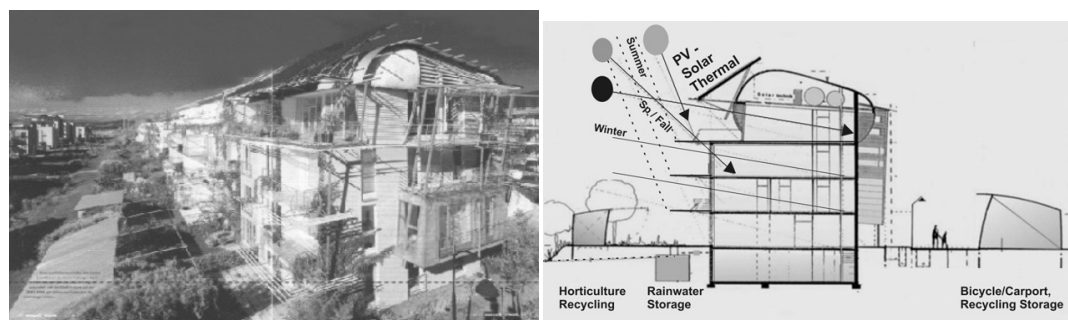

Figure 1: Solar low-energy town houses with re-used, recycled industrial elements, and materials, 1996, Architect Thomas Spiegelhalter. Image: Thomas Spiegelhalter. 
The energy policy targets low-energy-building standards (Fig. 1) with a 30-65 $\mathrm{kWh} / \mathrm{m}^{2}$ allowance for buildings and includes a variety of subsidies for photovoltaic's, passive and active solar thermal heating and cooling, rainwater reuse, storm water management, and increased building envelope efficiency.

Additional forms of large-scale renewable energy utilization are the district heating network from a combined heat and power plant using biogas from landfill. In both Rieselfeld and Vauban, combined heat and power plants are also fuelled by waste dust from saw mills in the black forest, first converting the dust into pellets in a compressing plant and then shipping them with bio-fuelled trucks directly to the adjacent district's co-generation plants. The result of this circular, ecocycle and balanced metabolism is the use of renewable energy source and the conversion of a waste stream into a productive resource of energy generation.

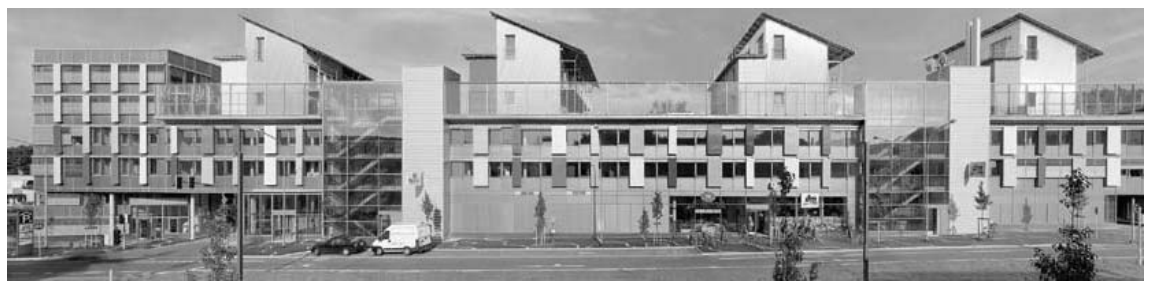

Figure 2: Sonnenschiff, plus-energy-houses, Architect Rolf Disch, Image: Th. Spiegelhalter.

\subsection{District Vauban}

Vauban is virtually complete with 5,000 residents. Its development began in 1994 on an area of 38 hectares located close to the city centre, on the former heavily polluted terrain of the French military forces and facilities once stationed. The existing rows of old trees were preserved and integrated in the new landscape of this high-density and mixed-used district. Low-energy (30-65 $\mathrm{kwh} / \mathrm{a} / \mathrm{m}^{2}$ calculated similar to the Swiss SIA 380/1 standard) and passive $\left(15 \mathrm{kwh} / \mathrm{a} / \mathrm{m}^{2}\right)$ building standards for heating are obligatory as well as zero fossil energy. Solar and geothermal technology mixed with daylighting, heat-recovery, natural ventilation strategies, rainwater storage and re-use, on-site grey water treatment, and on-site-recycling are standard for most buildings. Best of all, any excess energy that is produced can be sold to the public grid.

The entire neighborhood is traffic-calmed, with very few motor vehicle ownership and the few that exists are parked in either of the two garages that are solar powered at the perimeter of the district. The goal is to keep the inner area car-free, while increase bicycling and the use of public transportation. A new ecological sewage system within one pilot project (Baugruppe "Wohnen und Arbeiten") uses vacuum pipes to transport the sewage into a biogas plant where it is fermented anaerobically together with organic household waste. This then generates biogas, which is used for cooking and heating. The remaining waste water (grey-water) is cleaned in biofilm plants and returned to the water 
cycle [4]. Funded by the German Federal Ministry of Education and Research in 2001, the resource flow of the new district Freiburg-Vauban have been analyzed by the Öko-Institut (Institute for applied ecology) as part of the research project "Sustainable districts in urban conversion areas". The project examines ecological and economic effects for life cycle and regional material flows, in using GEMIS Life-Cycle-Analysis Software [5]. This is the first time that a complete urban neighborhood has been analyzed with respect to buildings, infrastructure, electricity supply, heat supply, water and waste, traffic, and private consumption with a full life-cycle perspective using regional data.

The following selected figures are provisional:

- Energy savings per year: 28 GJ (calculated as "CER", cumulative energy requirements).

- Reduction of CO2-equivalents per year: $2100 \mathrm{t}$.

- $\quad$ Reduction of sulphur-dioxide (SO2-) equivalents per year: $4 \mathrm{t}$.

- Saving of mineral resources per year: $1600 \mathrm{t}$. [6].

The briefly described LCA for Vauban, shows how a combination of inputoutput analysis, district characteristics, lifestyles, and household consumption data can be used to determine the environmental impact of consumption patterns in a new district. The change of the total environmental impact over time can be attributed to underlying variables such as efficiency gains, changes in consumption levels, structural changes, and changes in the population. This provides an understanding of causal factors influencing the development of ecocycles or circular metabolism strategies, which can be further developed in multiple models for better resource management planning. Several other funds could be mobilized for the community planning and urban ecology innovations in Vauban, such as from the German Environment Foundation and the EU program LIFE. Furthermore Vauban was presented as German Best Practice at the 1996 UN Habitat II conference in Istanbul, at the World Expo 2000 in Hannover, and at the World Expo 2010 in Shanghai.

\subsection{Case study no. 2}

\section{Stockholm, Sweden - district Hammarby Sjöstad}

Coordinates: $59^{\circ} 21^{\prime} \mathrm{N} 18^{\circ} 04^{\prime} \mathrm{E}$, Elevation: $278 \mathrm{~m}$

City Area: $188 \mathrm{~km}^{2}$, Municipalities: 11

Population City Area: 825,057 (11/11/2009), City Density 4,388.6/km²

Climate: HDD 4300, CDD 100

Solar Radiation: 1,981 hours of sunshine annually [7].

The Swedish capital Stockholm will be the first awarded European Green Capital in 2010 and has the ambitious target of becoming independent of fossil fuels by 2050. Environmental guidelines have been implemented to guide city management and purchasing contracts, to identify unacceptable impacts of practices, as well as the strategies to reduce GHGs. The amount of green house gas which each inhabitant of Stockholm releases is 50 percent lower than the national average, and since 1990 emissions per person have been reduced by 25 percent. All public transportation machines run on renewable fuels. The 
city's government is in the midst of assessing its environmental impacts with the goal of certification under the EU's Eco Management and Audit (EMAS) program [8].

\subsection{Ecocycle city district Hammarby Sjöstad (Stockholm, Sweden)}

Hammarby Sjöstad (roughly translated: Hammarvillage Sea City) is Stockholm's biggest urban development project. It expands the inner city close to water infrastructures, while converting an old industrial brownfield and harbor area with significant soil decontamination into an Ecocycle City. By 2015, Hammarby Sjöstad is projected to have 11,000 residential units for just over 25,000 people and a total of about 35,000 people will live and work in the adjacent area. As a former heavily polluted brownfield site, it was originally planned for development as part of Stockholm's bid for the 2004 Olympic Games. The bid failed, but work was already under way to clean and redevelop the area for the Olympic Village and it was decided to retain this momentum to create a positive change. The formerly derelict and polluted site was transformed with an emphasis on ecology and environmental sustainability.

At Hammarby Sjöstad, one of the key objectives was to show how the relationship between sewage processing, energy provision and waste handling in this local eco system can be structured to deliver wider social and environmental benefit. Emphasis was given to decontamination of the brownfield site, the provision of an effective public transport system to discourage the use of cars, the reduction of energy consumption, and water/waste recycling. Even the sewage is processed and reused to power the town's transport. Biogas is extracted from the digestion of sewage sludge from the wastewater treatment plant. It is then used to power the local cars and buses as well as 1,000 biogas stoves in the town. Low-Energy-Building standards with passive strategies for building alignments to sunlit 15 percent of the courtyard spaces for at least 4-5 hours at the spring and autumn equinoxes are mandatory. Heating for buildings is provided with renewable fuels, biogas products and reuse of waste heat coupled with energy-efficient buildings enclosure systems. In terms of water use savings most residents have managed to reduce their water consumption from 180 to about 150 liters/person/day. The aim is to reduce it even further to 100 liters/person/day by 2015. Energy consumption from transport has also been dramatically cut as the design of the town discourages private car use. Instead, there are several energy saving alternatives, including light rail, ferries, and car pools. By 2010, 80 percent of residents' journeys to work must be made on public transport, bicycle, or foot [9].

Hammarby Sjöstad has three different levels of waste management: They are building-based separating at source with various automated waste disposal chutes; Block-based recycling rooms for waste that do not belong in the building-based refuse chutes; And area-based hazardous waste collection point for waste that constitutes a danger to people and the environment. All refuse chutes are linked by underground pipes to a central collection station to which they are carried by vacuum suction. The collection stations accommodate advanced control systems that send the various fractions to the right container. 
There is a large container for each fraction which includes combustible domestic waste, food waste, and newspapers. The waste collected in the mobile automated waste disposal system ends up in underground tanks that are emptied by a refuse collection vehicle equipped with a vacuum suction system. There are separated tanks for each fraction, combustible domestic waste and food waste. The refuse collection vehicle stops at docking points where several buildings' waste tanks are emptied simultaneously, but only one fraction at a time per collection round.

The systems reduce transport energy, pollution, and noise in the area. Combustible waste is transported to the Högdalenverket plant in southern Stockholm where it is incinerated and recycled as heating and electricity for the buildings. Food waste is transported to Sofielund in Huddinge where it is composted and turned into soil. The ultimate aim is for food waste to be converted into biogas and bio-fertilizers, newspapers are delivered to paper recycling companies and then sent on to paper mills where they are turned into new paper. Paper, metal, glass, and plastic packaging are recycled as new packaging or as other products, and bulky waste, such as metal is recycled, or incinerated and used as heating and electricity. Electrical and electronic waste is disassembled and the materials are recycled and leftover materials are disposed on landfill sites [10].

\section{Conclusion}

Both closed-loop or eco-cycle district case studies in Freiburg and in Stockholm districts have made some of the most impressive progresses in the area of biomimicking nature, towards a better understanding of the circular metabolism of cities. They both have well implemented frameworks for monitoring, evaluating, and improving strategies towards the long-term viability of their innovations in sustainability, in technical-economic, social-cultural, and in governance terms. Both cities are trying to achieve its carbon neutral status in stationary energy provision and both have extremely high building energy efficiency standards. They have significantly reduced the resource-input, minimized pollution, and have advanced water and waste recycling practice underway. They developed low-carbon neighbourhoods within a high density public transport and their bicycle system network is radically less car dependent than most new areas in the world. Both cities are working on two different yearly eco-balancing and life-cycle assessments, and have increased awareness about linkages between land development, material flows, and cycles in the city and between the local, regional, and global environment. The policy makers and residents of Freiburg and Stockholm have been educated on the linear metabolism of the city and the imbalances in the city's imports of materials and exports of wastes. This led to support for work on sustainability and increased consideration for the ecological life-cycle improvements in urban planning that waste becomes a resource for other processes.

Can all the actions in support of ecocycles balancing achieve a completely, measureable, self-sufficient, carbon-neutral community by 2050 ? 
From a self-sufficiency point of view there is no such thing as a sustainable city. Cities have always been dependent on their hinterlands for food and other ecosystem goods and services [11]. The future challenge here is to develop a publicly easy accessible and commonly understandable eco-balancing tool or model that will have more direct input into the structural planning process and that can be benchmarked against global resource balancing levels according to IPCC targets. The World Business Council for Sustainable Development (WBCSD) recommends worldwide governments, businesses, and individuals to start to aggressively reduce energy use in new and existing buildings in order to reduce the planet's energy-related carbon footprint by 77 percent or 48 Gigatons (against the 2050 baseline) so as to stabilize CO2 levels to reach the degree required by the Intergovernmental Panel on Climate Change (IPCC). Urgent work is needed to develop a 'common carbon metric' with an integrated resource master plan and diversified renewable energy portfolio for the measurement of the carbon footprint of buildings and cities. This would help to make smart infrastructure and new building choices and ensure an economically and environmentally self-sufficient fossil-free infrastructure by 2050 .

In summary, circular metabolism strategies for cities, by its very nature cannot be compartmentalized into one city or country's ministerial language portfolio, a single-line entry in corporate business plans, or a sole area of NGO activism. Sustainable cities, while firmly an environmental issue is also an environmental threat that impacts every facet of government and public life from finance and planning to agriculture, health, employment, and transport. If both sides of the climate coin (emission reductions and adaptation) can be addressed, then perhaps many of the other sustainability challenges can also be addressed comprehensively, cohesively, and with a long-term lens to achieve a level of global circular metabolic resource measurement and management rather than in the segmented, piecemeal, and shortsighted ways of the past. The most important question arises from the following fact: The maximum ecological burden which world civilization can cope with will be reached before the limit of availability of finite resources. According to the findings of the Intergovernmental Panel on Climate Change (IPCC), climate gases will have to be reduced by at least 60 percent by 2050 if ecosphere collapse is to be avoided.

\section{Acknowledgement}

The authors would like to thank Dr Psych. Jose Nadine Garcon. Her comments have helped to improve this research paper.

\section{References}

[1] Pachauri, R.K. and Reisinger, A. (Eds.). "The Fourth Assessment Report of the Intergovernmental Panel on Climate Change", IPCC, Geneva, Switzerland. 2007, http://www.ipcc.ch/ 
[2] Oeko Institut Freiburg Report: Klimaschutz-Strategie der Stadt Freiburg Abschlussbericht Szenarien und Maßnahmenplan, Version 3.3, 2007 http://www.oeko.de/publikationen/jahresberichte/dok/656.php

[3] Referat für Internationale Kontakte, Büro für Nachhaltigkeit (International Affairs Department, Green City Office, Freiburg im Breisgau, Germany), http://www.fwtm.freiburg.de/servlet/PB/menu/1182949_11/index.html

[4] GEMIS, Life-Cycle-Software: Global Emission Model for Integrated Systems (GEMIS) Version 4.5, Oeko Institute Freiburg, Germany, http://www.oeko.de/service/gemis/en/

[5] Final report LIFE97 ENV/D/000469 "Umsetzung des Nachhaltigen Modellstadtteils Vauban", Technical Report, 100 pages, submitted to the European Commission, DG XI, on March 30, 2000 http://www.oeko.de/ service/cities

[6] World Weather Information Service, Stockholm, Sweden, http://www.degreedays.net/

[7] EU's Eco Management and Audit (EMAS) program http://ec.europa.eu/ environment/emas/index en.htm

[8] Hammarby Sjöstad, http://www.hammarbysjostad.se/

[9] Rees, W. E. "Urban ecosystems: the human dimension". Urban Ecosystems 1, 63-75, 1997; Rees, W. E. 2003. Understanding urban ecosystems: an ecological economics perspective. Pages 115-136 in A. R. Berkowitz, C. H. Nilon, and K. S. Hollweg, editors. Understanding urban ecosystems. A new frontier for science and education. Springer-Verlag, New York, New York,

[10] The World Business Council for Sustainable Development (WBCSD) http://www.wbcsd.org/templates/TemplateWBCSD5/layout.asp?MenuID=1

[11] Hermann Scheer. "The post-fossil future", Le Monde Diplomatique, France, June 2006 